\title{
Consumer Complaints Against Alcohol Advertisements: An Evaluation
}

Rob van Zanten

\section{Introduction}

Marketing communications play a pivotal role in the process of building and maintaining brand identity and brand equity, and in fact form a critical aspect in determining a company's ultimate success in the marketplace. Effective communications have become a priority for marketers in an increasingly competitive environment. Equally, however, marketing communications must be approached with a sense of obligation to the consumer and society, especially in 'sensitive' markets such as that of alcohol beverages.

There is considerable community concern that alcohol advertising might result in increased misuse of alcohol (Alcohol in Australia: Issues and Strategies, 2001). Because of the nature of the product, marketers of alcohol inevitably take on a heightened level of social responsibility in terms of its advertising and promotion. As much of the criticism against alcohol advertising is directed at Ready-to-Drink (RTD) advertising and its influence on 18 to 24 year olds (Dorsett and Dickerson, 2004), the focus of this article will be to investigate the complaints leveled at alcohol advertisements in Australia and find answers to the following two research questions:

1. What are the characteristics of the alcohol advertisements that attract complaints?

2. To what extent does RTD advertising account for the complaints?

A number of countries worldwide have experienced the emergence and growth of RTD beverages, and the results from this study may have resonance in these markets.

\section{Advertising Regulations in Australia}

The current self-regulatory system for alcohol advertising in Australia has been in force since 1998. Following the demise of the Advertising Standards Council in 1996, Australia's peak advertising body the Australian Association of National Advertisers (AANA) developed a new code relating to all advertisements, the Advertiser Code of Ethics. The Advertising Standards Board (ASB) established at the same time, deals with public complaints about advertisements and determines whether the Advertiser Code of Ethics

Biography

Rob van Zanten is a Lecturer at Waite Campus, The University of Adelaide. He was appointed in 2001 to the Wine Business Group of the University. His research interests include Internet marketing, integrated marketing communications, and alcohol advertising. 
Consumer

Complaints

Against Alcohol

Advertisements has been breached. The principal objective of the ASB is to maintain standards of taste and decency in advertising.

In August 2003 the National Committee for the Review of Alcohol Advertising (NCRAA) released the findings of its inquiry into the effectiveness of the Australian system of alcohol advertising self-regulation. The report noted that the overwhelming majority of alcohol advertising complaints (95\%) were dealt with by the ASB under the general Advertiser Code of Ethics. The remaining $5 \%$ of complaints were referred by the ASB to the Complaints Adjudication Panel, a body that administers the alcohol advertising specific Alcohol Beverage Advertising Code (ABAC). The ABAC complements the AANA Advertiser Code of Ethics and provides for more specific guidance in relation to the advertising of alcohol beverages.

This current study is based upon the complaints reviewed by the ASB under the Advertiser Code of Ethics and does not include complaints reviewed by the Complaints Adjudication Panel due to the unavailability of this data. Although the NCRAA recommended alcohol advertising should continue to be self-regulated in Australia, the report also made it clear that the option of future government regulation could not be ruled out (National Committee for the Review of Alcohol Advertising, 2003). Alcohol advertisers more than ever need to be aware of their social responsibility and make efforts to avoid drawing unnecessary attention to the alcohol industry. The use of inappropriate images and advertising appeals will only make the advertisers' position more vulnerable in the eyes of the advertising policing organisations (Lass and Hart, 2004).

\section{The Data - ASB Case Reports}

The ASB is charged with the maintenance of taste and decency in advertising, having regard to prevailing community standards. Any member of the general public can lodge a complaint with the ASB. In accordance with Section 2 of the Advertiser Code of Ethics (the 'Code') complaints can be made on grounds of discrimination or vilification, violence, language, portrayal of sex/sexuality/nudity, health and safety, and alarm or distress to children. Complaints are assessed and evaluated by members of the ASB, who consider whether the advertisement in question breaches Section 2 of the Code. The ASB meets about once per month, with body complainants and advertisers kept informed of the process and provided with a written Case Report at its conclusion. The process can take several months, and in some instances a particular case can straddle adjacent years. In this present study, cases have been allocated to the year in which the determination was made rather than the year in which the complaint was lodged.

The ASB Case Reports form the data set used in this article. All advertisements subject to complaints from 1999 to 2003 that dealt with alcohol were included in the study - 60 cases (advertisements) in all. Each Case Report provided details of the advertiser, product category, communication 
medium and the nature of the complaint, together with a description of the ad, extracts from the complainant's submission, and the basis of the Board's determination. The ASB dismissed all complaints lodged in relation to alcohol advertisements assessed in the period 1999 to 2003 (Advertising Standards Board, Case Reports 1999-2003).

\begin{tabular}{|l|l|l|l|l|}
\hline \multicolumn{5}{|c|}{ Table 1: Product/service categories attracting complaints } \\
\hline Category & $\mathbf{2 0 0 0}(\mathbf{\%})$ & $\mathbf{2 0 0 1}(\mathbf{\%})$ & $\mathbf{2 0 0 2}(\mathbf{\%})$ & $\mathbf{2 0 0 3}(\mathbf{\%})$ \\
\hline Clothing & 16.1 & 7.3 & 27.9 & 14.1 \\
\hline Food & 13.8 & 22.3 & 25.4 & 13.5 \\
\hline Vehicles & 10.00 & 11.7 & 10.3 & 15.8 \\
\hline Retail & 3.8 & 6.0 & 6.4 & 0.7 \\
\hline Alcohol & $\mathbf{4 . 8}$ & $\mathbf{2 . 4}$ & $\mathbf{6 . 0}$ & $\mathbf{1 1 . 6}$ \\
\hline Toiletries & 10.0 & 4.2 & 4.0 & 15.7 \\
\hline House goods/services & 5.3 & 8.3 & 3.1 & 4.7 \\
\hline Community awareness & 5.0 & 3.0 & 2.6 & 0.9 \\
\hline Health products & 2.7 & 5.5 & 2.4 & 3.1 \\
\hline Entertainment & 2.9 & 3.7 & 1.5 & 1.2 \\
\hline Finance/investment & 1.2 & 3.2 & 0.7 & 1.0 \\
\hline Telecommunications & 2.7 & 6.7 & 1.4 & 4.8 \\
\hline Media & 5.5 & 3.0 & 0.7 & 4.0 \\
\hline Restaurants & 7.9 & 1.0 & 0.3 & 0.3 \\
\hline Other & 8.3 & 11.7 & 7.3 & 8.6 \\
\hline Total & 100.0 & 100.0 & 100.0 & 100.0 \\
\hline Souce: Adver & & & \\
\hline
\end{tabular}

Source: Advertising Standards Bureau

Every year the ASB receives complaints in relation to over 400 advertisements. Although a relatively small number of advertisements deal with alcohol (an average of 12 per year over the study period), the actual number of complaints received with respect to these can in some years represent a significant proportion of the total number of complaints received for all product categories (see Table 1). The ASB does not divulge the number of complaints received by each advertisement, although it does provide limited aggregate data. These data show that women complain about ads more frequently than do men. Of the 515 complaints received in relation to ads dealing with alcohol in the years 2000 to 2003 inclusive, $70 \%$ of the complaints were from women. This compares with an average of $60 \%$ for all product categories over the same time period. 


\begin{tabular}{|l|l|l|l|l|l|l|l|l|l|}
\hline \multicolumn{7}{|c|}{ Table 2: Alcohol advertisements attracting complaints (by media type) } \\
\hline Medium & 1999 & 2000 & 2001 & 2002 & 2003 & $\begin{array}{l}\text { Alcohol 1999 } \\
\text { to 2003 }\end{array}$ & $\begin{array}{l}\text { Alcohol } \\
\text { 1999 to 2003 } \\
(\%)\end{array}$ & $\begin{array}{l}\text { All } \\
\text { Categories } \\
(\%)\end{array}$ \\
\hline Television & 6 & 6 & 5 & 8 & 10 & 35 & 58.3 & 69.3 \\
\hline Outdoor & 1 & 3 & 2 & 2 & 2 & 10 & 16.7 & 17.9 \\
\hline Print & 2 & 2 & 3 & 1 & 1 & 9 & 15.0 & 8.6 \\
\hline Radio & 1 & 1 & - & 2 & 1 & 5 & 8.3 & 1.6 \\
\hline Transport & - & - & - & - & 1 & 1 & 1.7 & 0.3 \\
\hline Multiple media & - & - & - & - & - & - & - & 1.9 \\
\hline Cinema & - & - & - & - & - & - & - & 0.3 \\
\hline Pay TV & - & - & - & - & - & - & - & 0.1 \\
\hline Total & 10 & 12 & 10 & 13 & 15 & 60 & 100.0 & 100.0 \\
\hline $\begin{array}{l}\text { Note 1: Total complaints for all product and service categories (including alcohol) for the period } 2000 \text { to } 2003 \\
\text { inclusive. } \\
\text { Source: Advertising Standards Bureau }\end{array}$ &
\end{tabular}

\section{Consumer}

Complaints

Against Alcohol

Advertisements

Table 2 shows the communication media associated with the alcohol ads that were subject to complaint in the period 1999 to 2003. Not surprisingly, television emerged as the medium that was associated with the highest number of ads subject to complaint, most likely because of the medium's potential for wide coverage and high reach. Outdoor and print occupy somewhat distant second and third places respectively. Table 3 shows the grounds for complaint. The discriminatory portrayal of people and the portrayal of sex/sexuality/nudity represented the grounds for complaint cited in $29.2 \%$ and $28.1 \%$ of alcohol ads respectively.

A breakdown of alcohol ads into beverage categories is presented in Table 4. Beer was the category most subject to complaint, with a 'share-of-complaint' (SOC) of 44\%. Although this figure is high, it is equivalent to the beverage's share-of-voice (SOV) figure, and is in fact somewhat less than its share-of-market (SOM). At the other end of the spectrum, the SOC for wine is just 5\% well below both its SOV and SOM. The most likely explanation for this is the category's presumed greater use of communication methods other than advertising (when compared to beer and spirits), and the generally conservative nature of much wine-related advertising. 
Table 3: Alcohol advertisements attracting complaints (by issue type)

\begin{tabular}{|c|c|c|c|c|c|c|c|c|}
\hline Complaint Issue $^{1}$ & 1999 & 2000 & 2001 & 2002 & 2003 & $\begin{array}{l}\text { Alcohol }^{2} \\
1999 \text { to } \\
2003\end{array}$ & $\begin{array}{l}\text { Alcohol } \\
1999 \text { to } \\
2003(\%)\end{array}$ & $\begin{array}{l}\mathrm{All}^{3} \\
\text { Categories } \\
(\%)\end{array}$ \\
\hline $\begin{array}{l}\text { Discrimination/ } \\
\text { Vilification }\end{array}$ & 5 & 7 & 3 & 7 & 4 & 26 & 29.2 & 22.3 \\
\hline Violence & 1 & 1 & 3 & 1 & 1 & 7 & 7.9 & 9.3 \\
\hline Language & - & 1 & - & - & 2 & 3 & 3.4 & 7.9 \\
\hline $\begin{array}{l}\text { Portrayal of sex/nu- } \\
\text { dity }\end{array}$ & 2 & 7 & 5 & 7 & 4 & 25 & 28.1 & 29.0 \\
\hline Health \& Safety & 3 & 2 & 4 & 5 & 5 & 19 & 21.3 & 14.4 \\
\hline $\begin{array}{l}\text { Alarm/distress to } \\
\text { children }\end{array}$ & - & - & - & - & 1 & 1 & 1.1 & 2.9 \\
\hline Other & 2 & - & 3 & 2 & 1 & 8 & 9.0 & 14.2 \\
\hline Total & 13 & 18 & 18 & 22 & 18 & 89 & 100.0 & 100.0 \\
\hline
\end{tabular}

Note 1: In some cases individual advertisements attracted complaints on more than one issue.

Note 2: Issues raised in relation to the 60 alcohol-related complaint cases for the years 1999 to 2003 inclusive.

Note 3: Issues for all product and service categories (including alcohol) for the period 2000 to 2003 inclusive.

Source: Advertising Standards Bureau

Table 4: Alcohol advertisements attracting complaints (by beverage category)

\begin{tabular}{|l|l|l|l|l|l|l|l|l|l|l|}
\hline Beverage & 1999 & 2000 & 2001 & 2002 & 2003 & $\begin{array}{l}\text { Total } \\
1999 \\
2003\end{array}$ & $\begin{array}{l}\text { SOC } \\
\%\end{array}$ & SOM $\mathbf{1} \%$ & $\begin{array}{l}\text { Ad } \\
\text { Spend } \\
\text { mil }\end{array}$ & $\begin{array}{l}\text { SOV } \\
\%\end{array}$ \\
\hline Beer & 5 & 4 & 3 & 6 & 8 & 26 & 44 & 50 & 43.1 & 44.9 \\
\hline Wine & 1 & 1 & 1 & - & - & 3 & 5 & 30 & 16.7 & 17.4 \\
\hline Spirits & 1 & 2 & 2 & 5 & 4 & 14 & 23 & 12 & 23.0 & 24.0 \\
\hline $\begin{array}{l}\text { Spirits } \\
\text { (RTD) }\end{array}$ & 2 & 5 & 3 & 1 & 3 & 14 & 23 & 8 & 11.4 & 11.9 \\
\hline Cider & 1 & - & 1 & 1 & - & 3 & 5 & 0 & 1.7 & 1.8 \\
\hline Total & 10 & 12 & 10 & 13 & 15 & 60 & 100 & 100 & 95.9 & 100.0 \\
\hline
\end{tabular}

Note 1: Alcohol beverage category market share for the financial year 2002/2003. Market share for cider not provided. Source: Distilled Spirits Industry Council of Australia, http://www.dsica.com.au/pdfs/measures.pdf. Website accessed September 2004.

Note: 2 Alcohol advertising spend in Australian dollars (millions) for the period November 2002 to October 2003.

Source: AC Nielsen Media Research - AdEx, (Clancy, 2003). Spend does not include online. 


\section{Consumer}

Complaints

Against Alcohol

Advertisements

Similar to beer, the SOC of the spirits category is equivalent to its $\mathrm{SOV}$, although spirits advertising is considerably 'louder' when SOM is taken into account. With RTD (Ready-to-Drink) beverages however, not only is the advertising 'loud' (SOV is one-and-a-half times greater than SOM), it is 'offensively loud' (SOC is three times greater than SOM). RTDs have a very disproportionate share of advertising complaints, and the situation may in fact be underrepresented. Some ads that were placed in the spirits category may have actually been for RTDs but could not be classified as such because the Case Reports and product descriptions did not specifically refer to RTDs.

\section{Content Analysis - Advertising Appeal}

According to Clow and Baack (2002), advertisers when developing an advertisement, usually select from one of seven major types of advertising appeal - fear, humour, sex, music, rationality, emotions and scarcity. In order to answer the research question, content analysis was carried out on the alcohol ads that were subject to complaint in the period 1999 to 2003. Each ad (as described by the ASB in the relevant Case Report) was assessed for the predominant advertising appeal utilised. In addition to the ad description, the judges could make use of the complainants' and Board's comments to better help form their judgements. In accordance with the recommended procedures for content analysis (Kassarjian, 1997), multiple judges were used. In this study, three coders were asked independently to assign one of the six types of appeal to each advertisement (music was regarded as an inapplicable appeal in the light of the text-based nature of the data). An appeal was assigned to an ad when two of the three coders agreed. In an effort to reduce subjectivity, coders were asked to assess appeals in terms of intent rather than personal likes or dislikes. The coders were unable to classify the predominant appeal in only one of the 60 ads. The results of the content analysis are displayed in Table 5. Over $96 \%$ o alcohol ads attracting complaints used either a humorous or a sexual appeal. None of the ads used fear, rationality or scarcity in their appeal. The judges were able to agree unanimously on the humorous intent of $46(98 \%)$ of the 47 humorous ads, and the sexual intent of $8(73 \%)$ of the 11 sexual ads. In the remaining humorous and sexual ads, two of the three judges were in agreement.

The judges also coded the humorous ads for the type of humour used, with the agreement of two out of three coders necessary for a type to be assigned. The current research utilised the humour typology originally developed by Freud (1905) that places all humour into one of three classifications: nonsense, aggressive or sexual. Freud made an important distinction between innocent and tendentious humour (Billig, 2003; Freud, 1905 [1976]). The pleasure derived from innocent (abstract or nonsense humour is linked in some way to its technique, for example, a simply play on words. Tendentious humour on the other hand fulfils a deeper psychological function, in that it allows repressed desires to be voiced. Freud argued that tendentious 
humour expresses either aggressive or sexual impulses (or both) (Billig, 2002; Goldstein and McGhee, 1972). The aggressive purpose of humour may be fulfilled through hostility, satire, sarcasm or ridicule. The sexual purpose is fulfilled through sexual suggestiveness or exposure. Table 6 provides examples of alcohol advertisements from the ASB Case Reports that illustrate the various appeals described above. The ad descriptions and complainants' extracts have been transcribed verbatim, including punctuation.

\section{Consumer \\ Complaints \\ Against Alcohol Advertisements}

Table 5: Alcohol advertisements attracting complaints (by predominant appeal)

\begin{tabular}{|l|l|l|l|l|l|l|l|}
\hline Advertising Appeal & 1999 & 2000 & 2001 & 2002 & 2003 & Total & $\begin{array}{l}\text { Total } \\
(\%)\end{array}$ \\
\hline $\begin{array}{l}\text { Humour aggressive/ } \\
\text { satirical }\end{array}$ & 4 & 2 & 5 & 5 & 8 & 25 & 40.0 \\
\hline Sexual & 2 & 2 & 2 & 3 & 2 & 11 & 18.3 \\
\hline Nonsense/absurd & 2 & 4 & - & 2 & 2 & 10 & 16.7 \\
\hline Unclassified & 1 & - & - & - & 1 & 2 & 3.3 \\
\hline Sexual & 1 & 3 & 3 & 3 & 1 & 11 & 18.3 \\
\hline Emotional & - & - & - & - & 1 & 1 & 1.7 \\
\hline Unclassified & - & 1 & - & - & - & 1 & 1.7 \\
\hline Total & 10 & 12 & 10 & 13 & 15 & 60 & 100.0 \\
\hline
\end{tabular}

\begin{tabular}{|l|l|l|l|}
\hline \multicolumn{3}{|c|}{ Table 6: Examples of ads categorized by appeal type } \\
\hline $\begin{array}{l}\text { Appeal } \\
\text { Type }\end{array}$ & $\begin{array}{l}\text { Advertiser \& } \\
\text { Medium }\end{array}$ & $\begin{array}{l}\text { Reference } \\
\text { Number }\end{array}$ & Description of ad, and complaint \\
\hline Sexual & $\begin{array}{l}\text { Yalumba (Antipodean } \\
\text { Wine Company) }\end{array}$ & $15 / 1999$ & $\begin{array}{l}\text { The print advertisement comprises a reasonable sized clear pho- } \\
\text { tograph of a woman's nude lower abdomen and pubic area. Her } \\
\text { pubic area has been shaved into 'stripes'. Alongside this is a } \\
\text { much smaller photograph of the top half of a bottle of wine. The } \\
\text { plastic/foil on the top of the bottle is striped. The name of the } \\
\text { wine is 'Antipodean'. The words alongside the bottle are, 'Em- } \\
\text { brace Change'. } \\
\text { The Complaint: } \\
\text { "...not only is (the ad campaign) offensive but it is blatantly sex- } \\
\text { ist in its market approach. For example, in a 'teen' magazine } \\
\text { such as Rolling Stone, we have a revealing advertisement of a } \\
\text { shaved woman's pubic hair and in a woman's magazine such as } \\
\text { Elle, we have the back of man's head shaved. Where is the } \\
\text { equality in this? ...I am sick to death of seeing advertisements } \\
\text { blatantly using naked or half naked women to sell a product...if } \\
\text { a penis was on display all hell would break loose." }\end{array}$ \\
\hline
\end{tabular}




\begin{tabular}{|c|c|c|c|}
\hline Emotional & $\begin{array}{l}\text { Carlton \& United } \\
\text { Breweries Ltd. } \\
\text { (Carlton Sterling } \\
\text { Beer) } \\
\text { Television }\end{array}$ & $90 / 2003$ & $\begin{array}{l}\text { This television advertisement opens on a public house scene, } \\
\text { with a man entering and being immediately captivated by what } \\
\text { he sees across the bar room. To a romantic soundtrack, the man } \\
\text { makes his way to the bar and a bottle of Carlton Sterling. The } \\
\text { advertisement ends with voiceover-supported caption reading: } \\
\text { "Carlton Sterling. The beer lovers' light.' } \\
\text { The Complaint: } \\
\text { "I know that the beer is a light beer and that ad is trying to cast } \\
\text { this beer in a positive light, but I found the ad offensive and mis- } \\
\text { leading because it attributed more power and allure than was } \\
\text { appropriate to this beer." }\end{array}$ \\
\hline $\begin{array}{l}\text { Hu- } \\
\text { mour-sex- } \\
\text { ual }\end{array}$ & $\begin{array}{l}\text { Lion Nathan Australia } \\
\text { Pty Ltd. (Tooheys } \\
\text { Bar) } \\
\text { Television }\end{array}$ & $172 / 2003$ & $\begin{array}{l}\text { The television advertisement opens on a beach scene, where a } \\
\text { group of young men are playing a soccer game. Two young } \\
\text { women arrive and ask if they may join in. When one of the } \\
\text { young men scores a goal, he lifts his shirt over his head in the } \\
\text { manner of some professional soccer players. When one of the } \\
\text { young women subsequently scores a goal, she does the same } \\
\text { thing, running away from the camera view to the evident delight } \\
\text { of the young men in front of her. The young men are next seen } \\
\text { drinking cans of beer in an after-match celebration. A superim- } \\
\text { posed caption incorporating a Tooheys logo reads: 'Not a spon- } \\
\text { sor of the World Cup,' which changes to 'A sponsor of the D } \\
\text { Cup.' } \\
\text { The Complaint: } \\
\text { "The smug looks on the men only serve to reinforce the demean- } \\
\text { ing attitude to women as objects to be exploited. Additionally, I } \\
\text { find it very demeaning when the advertisement ends with the } \\
\text { words 'Not a sponsor of the World Cup, a sponsor of the D Cup.' } \\
\text { An obvius and distasteful reference to a woman's bust size for a } \\
\text { product that has nothing to with women's clothes." }\end{array}$ \\
\hline $\begin{array}{l}\text { Humour- } \\
\text { Aggres- } \\
\text { sive/ } \\
\text { Satirical }\end{array}$ & $\begin{array}{l}\text { Swift \& Moore (Ca- } \\
\text { nadian Club Whisky) } \\
\text { Television }\end{array}$ & $287 / 2002$ & $\begin{array}{l}\text { This television advertisement depicts a group of four men play- } \\
\text { ing what appears to be a game of golf on frozen land. The men } \\
\text { are portrayed to be enjoying themselves until one of the players } \\
\text { hits the ball towards a hole in which a seal appears and takes the } \\
\text { ball. One of the men is heard to say: 'Well, I guess that's the last } \\
\text { hole,' and the men are then seen to return indoors to a bar-like } \\
\text { room. A voice-over states: 'Canadians have a style of their own, } \\
\text { just like their whisky - Canadian Club Style Whisky.' One of the } \\
\text { men then starts to leave the room, and when asked where he is } \\
\text { going, he replies: 'I'm going to get my ball back from that damn } \\
\text { seal.' One of the other men then asks: 'Do you wanna borrow } \\
\text { my club?' The man does not reply and the final scene depicts a } \\
\text { bottle of Canadian Club Style Whisky with a voice-over that } \\
\text { states: 'Canadian Club. Similar yet different.' } \\
\text { The Complaint } \\
\text { "...This is a sick joke and extremely offensive. In Canada seal } \\
\text { pups are still being clubbed by the thousands, though the large } \\
\text { majority of the population believe this was outlawed many years } \\
\text { ago, this vile, cruel practice is still being used today. A joke } \\
\text { about this in any format is unacceptable!"” } \\
\text { "...The commercial...makes an oblique reference to seal club- } \\
\text { bing. I find this sad and inappropriate, and completely unneces- } \\
\text { sary..." }\end{array}$ \\
\hline
\end{tabular}




\begin{tabular}{|l|l|l|l|}
\hline $\begin{array}{l}\text { Hu- } \\
\text { mour-non- } \\
\text { sense }\end{array}$ & $\begin{array}{l}\text { United Distillers \& } \\
\text { Vintners, Australia. } \\
\text { (Bundaberg Rum and } \\
\text { Coke, RTD) }\end{array}$ & $81 / 1999$ & $\begin{array}{l}\text { The radio advertisement includes the following script (male } \\
\text { voiceover): } \\
\text { "You go to the dentist for a check up and he ends up doing more } \\
\text { construction work than the Sydney Olympics... Do } \\
\text { you?........Go back to work speaking like the elephant } \\
\text { man?...b...dribble all over your boss?... or c...stick to a liquid } \\
\text { diet and have a bundy and cola for dinner... See you can solve } \\
\text { anything with a bundy and cola..." } \\
\text { The Complaint: } \\
\text { "I don't believe I need to insult anyone's intelligence by elabo- } \\
\text { rating on how devastating the effect of mixing drugs and alcohol } \\
\text { can be. Let alone the fact that alcohol does not have a very good } \\
\text { painkilling effect until one is quite drunk - hardly a responsible } \\
\text { thing to encourage. This advertisement has the potential to cause } \\
\text { grief. I recognise the right of Bundy and Cola company to adver- } \\
\text { tise their product rather but Australian society has enough trou- } \\
\text { ble with alcohol abuse and its repercussions without } \\
\text { encouraging alcohol as a cure-all for all life's hassles especially } \\
\text { physical pain." }\end{array}$ \\
\hline
\end{tabular}

With respect to the ads that were based upon humourous appeals, the research found that $51 \%$ had aggressive content, $23 \%$ sexual content, while $21 \%$ represented nonsense or innocent humour. The judges were able to agree unanimously on the aggressive intent of $21(87 \%)$ of the aggressive-humour ads, the sexual intent of $11(100 \%)$ of the sexual-humour ads, and the innocent nature of $8(80 \%)$ of the nonsense-humour ads. With the remaining humorous ads, two of the three judges were in agreement with respect to the type of humour, although two humorous ads could not be classified.

\section{Discussion}

Three types of major appeal attracted complaints - emotional, sexual and humorous. Emotional appeals help create a bond with consumers. Commonly used emotions in advertising are: trust, reliability, security, happiness, romance, friendship, anger and contentment. Sexual appeals are used in advertising to create attention, and build brand awareness (Lass and Hart, 2004), but if the viewer believes the ad is in poor taste or demeaning, negative feelings about the brand will result (Clow and Baack, 2002). Humorous appeals are useful in cutting through advertising clutter and enhancing recall (Wolfe, 1998). This latter effect seems to work with young and older consumers alike. One study has shown that humorous ads for alcohol brands figure among the best-recalled ads mentioned by children in focus groups (Brand-savvy youngsters no small beer, 2004). In another study, children aged nine to 15 years overwhelmingly preferred TV beer ads that were delivered with humour rather than with product-oriented elements (Waiters, et al., 2001).

Despite humour' undoubted advantages, it has it pitfalls. Humour is often perceived differently amongst people, for example, among those from different cultural backgrounds (Weinberger and Gulas, 1992). The response to humour by audience members can be very idiosyncratic: sexual humour, 
Consumer

Complaints

Against Alcohol Advertisements

satire and other forms of aggressive humour may generate strong positive feelings in some audience members and strong negative feelings in others (Weinberger and Gulas, 1992). According to Wolfe (1998) sarcasm and jokes made at another's expense are popular with younger audiences, but are likely to backfire with the baby-boomer generation (40 to 60 year-olds). The idiosyncratic response by viewers to humour means that humour is perhaps a more risky approach than other advertising appeals and it should therefore be used with care.

The risky nature of the humorous appeal is given support by the results of this study. Of the 60 ads that attracted complaints in the years 1999 to $2003,78 \%$ had a humorous intent. Furthermore, $74 \%$ of these had an aggressive or sexual content. This finding is not surprising as much alcohol advertising, especially beer advertising, is directed towards a (presumably) male-dominated audience. Weinberger and Gulas (1992) suggest that men appear to enjoy aggressive and sexual humour more than women do, and women have a greater appreciation for nonsensical humour. They point out that this finding should be treated with caution, however, as the situation may be reversed for sexual or gender-based humour produced for a female audience.

$18 \%$ of the ads that attracted complaints used a direct sexual appeal, but this rises to $37 \%$ when both direct and humorous sexual appeals are taken into account. The use of sexual imagery is a common approach in alcohol advertising, and helps create attention and build brand awareness, but advertisers need to study the target market closely as female consumers, who are much less appreciative of the use of sex in alcohol ads, may be alienated (Lass and Hart, 2004).

Only three wine ads made an appearance on the list of ads attracting complaints. A possible interpretation of this finding may be that wine advertisers have shied away from using the more risky types of advertising appeals, i.e. humorous and sexual appeals, and utilised in their place emotional, rational, scarcity and other appeals. Although this approach would avoid the potential for attracting complaints, the downside is that the ads may be perceived as dull and boring. The typical wine ad has indeed been described as "clinical, dull and unoriginal" (Caputo, 2003). According to Caputo, the wine industry needs to use more humour and fun in its advertising, and move away from the traditional glamorised-bottle ads, passionate-winemaker ads, scenic-vineyard ads, and people-enjoying-wine-ads. The problem with this advice is that it could well lead to greater consumer complaint behaviour, and the advertisements may not in any event find resonance with those older more conservative wine drinking consumers.

Wine purchase behaviour in fact spans the involvement continuum (Quester and Smart, 1996). Involvement ranges from low in the case of quaffing wines through to high when premium and icon wines are consid- 
ered. Research has shown that low involvement products are better suited to humorous ad treatments than are high involvement products (Weinberger and Gulas, 1992). A study that examined the effectiveness of humour across product groups found that humour appeared to be very effective in enhancing attention and recall for 'yellow' goods (low involvement, expressive goods) such as snack foods, desserts, beer, alcohol, and tobacco products (Spotts, et al., 1997). Quaffing or 'jug' wine would fall into this category. Consumers spend little time seeking information about these products, nor spend much time attending to ads about them. The ads can therefore be simple and humorous.

Humour is less effective for higher involvement and functional goods, and indeed appears to have a negative impact upon ad performance for 'red goods' such as fashion clothing, hair colouring and jewellery (Spotts, et al., 1997). These higher involvement expressive goods (including the more expensive premium and icon wines) are assumed to have a relationship with the consumer's personality, and making fun of such products may be considered threatening. According to Spotts, et al. (1997) the use of humour should be limited to low involvement yellow goods, such as beer. With wine products ranging from low to high involvement, the situation for wine advertisers is therefore a problematical one. The current study, limited as it is to alcohol ads that attracted complaints, provides indirect support to Caputo's claim (2003) that wine advertisers have largely adopted a 'safe' approach and avoided the use of humour altogether.

\section{Limitations of the Study}

The limitations of this study relate largely to the nature of the data set. The ASB Case Reports, although uniform in presentation, represent 'second hand' interpretations of the original alcohol advertisements. The ambience and character of some ads are difficult to convey via text descriptions, especially in the case of television and radio ads. Although intercoder reliability in this study was predominantly within the $85 \%$ limit recommended by Kassarjian (1977), coders may have found it easier to identify the advertising appeal and message intent from viewing the original ad rather than a written description of it. Further, music as an appeal could have been included within the set of appeals under consideration.

Although the study included all the alcohol ads reviewed by the ASB in the years 1999 to 2003, this only amounted to 60 ads in total. The study also had limitations with respect to the availability of demographic data other than in aggregate form. The ASB does not divulge demographic and complaint data (other than the extracts contained in the Case Reports) in relation to specific advertisements. 


\section{Conclusion}

Consumer

Complaints

Against Alcohol

Advertisements

This study showed that advertisements for beer, spirits and especially RTDs (when SOC versus SOM is considered) attracted the greatest number of complaints in the period 1999 to 2003. Wine advertisements played a negligible role. Although a recent study found RTD advertising was not related to overall alcohol consumption amongst the 18-24 age group (Dorsett and Dickerson, 2004), the findings from this current study provides insight as to why RTD advertising has been singled out for particular criticism.

Over $96 \%$ of alcohol ads attracting complaints used either a humorous or a sexual advertising appeal, and of the humorous ads $51 \%$ had an aggressive and $23 \%$ a sexual content. Nonsense humour played a lesser role, while rational, emotional, fear, and scarcity appeals made no impact upon the findings. The study provides solid evidence for the risky nature of the humorous appeal, and highlights the need for alcohol advertisers to use humour with caution. According to the Ministerial Council on Drug Strategy (Alcohol in Australia: Issues and Strategies, 2001) advertisements using animation, humour or rock music are particularly attractive to young people. Although it could be argued that the complaints against RTD ads and alcohol ads in general represent the views of isolated individuals, these very complaints inevitably draw the attention of policymakers and consequently may make the case for continued alcohol advertising self-regulation more difficult to sustain. 


\section{References}

Advertising Standards Board, Case Reports 1999-2003: Advertising Standards Bureau Ltd., Canberra, Australia.

Alcohol in Australia: Issues and Strategies (2001) A background paper to the National Alcohol Strategy: A Plan for Action 2001 to 2003/04: Ministerial Council on Drug Strategy, Commonwealth of Australia.

Billig, M. (2002) "Freud and the language of humour." The Psychologist, 15(9), pp.452-455.

Brand-savvy youngsters no small beer (2004). The Australian, p.17.

Caputo, T. (2003) "Why are wine ads so boring?" Wines and Vines, 84(12), pp.32-35.

Clancy, S. (2003) "Hangover warning: Alcohol advertising treads a fine line when it comes to young adults.” B\&T Weekly, pp.12-13.

Clow, K.E., Baack, D. (2002) Integrated Advertising, Promotion, and Marketing Communications. Upper Saddle River, New Jersey: Prentice Hall.

Dorsett, J., Dickerson, S. (2004) "Advertising and alcohol consumption in the UK." International Journal of Advertising, 23(2), pp.149-171.

Freud, S. (1905)[1976] Jokes and Their Relation to the Unconscious. New York: Penguin.

Goldsten, J.H. McGhee, P.E. (1972) The Psychology of Humor - Theoretical Perspectives and Empirical Issues. New York: Academic Press.

Kassarjian, H.H. (1977) “Content analysis in consumer research.” Journal of Consumer Research, 4(1), pp.8-18.

Lass, P., Hart, S. (2004) "National cultures, values and lifestyles influencing consumers' perception towards sexual imagery in alcohol advertising: An exploratory study in the UK, Germany and Italy." Journal of Marketing Management, 20(5/6), pp.607-623.

National Committee for the Review of Alcohol Advertising (2003). Review of the Self-Regulatory System for Alcohol Advertising: Report to the Ministerial Council of Drug Strategy, Minister for Health Victoria.

Quester, P.G., Smart, J. (1996) "Produce involvement in consumer wine purchases: Its demographic determinants and influence on choice attributes." International Journal of Wine Marketing, 8(3/4), pp.37-56. 
Consumer

Complaints

Against Alcohol

Advertisements
Spotts, H.E., Weinberger, M.G., Parsons, A.L. (1997) "Assessing the use and impact of humor on advertising effectiveness: A contingency approach." Journal of Advertising, 26(3), pp.17-32.

Waiters, E.D., Treno, A.J., Grube, J.W. (2001) "Alcohol advertising and youth: A focus-group analysis of what young people find appealing in alcohol advertising." Contemporary Drug Problems, 28(4), pp.695-719.

Weinberger, M.G., Gulas, C.S. (1992) "The impact of humor in advertising: A review. Journal of Advertising, 21(4), pp.35-59.

Wolfe, D.B. (1998) "Boomer humor." American Demographics, 20(7), pp.22-23. 